\title{
Inhibition of Liver Fibrosis by L-Azetidine-2-Carboxylic Acid in Rats Treated with Carbon Tetrachloride
}

\author{
Marcos RojKIND \\ From the Departamento de Biología Celular, Centro de Investigación y de \\ Estudios Avanzados del IPN, México 14, D. F.
}

A B S T R A C T L-Azetidine-2-carboxylic acid (AZC), an analogue of proline, has been shown to partially ameliorate hepatic cirrhosis induced in rats by $\mathrm{CCl}_{4}$. AZC caused a diminution in formation of collagen in the liver accompanied by a relative decrease in the pool of free proline. The synthesis of noncollagenous proteins in the livers of treated rats did not appear to be affected.

\section{INTRODUCTION}

The large increase in collagen observed in the livers of patients with hepatic cirrhosis (1) or in the livers of rats made cirrhotic by chronic administration of $\mathrm{CCl}_{4}$ $(2,3)$ or of ethanol (4) is largely due to de novo synthesis. In these cases, the increase in collagen is accompanied by a parallel increase in the pool of free proline and a decrease in the pool of free glutamic acid $(3,5)$. The increase in proline apparently occurs principally in the liver (5) and is due in part to more active synthesis from glutamic acid (3). The suggestion has been made that the pool of proline could regulate collagen biosynthesis by modulating the amount of aminoacylproline tRNA available ( 3 ). From these considerations one may infer that the biosynthesis of collagen could be inhibited by interference with the conversion of glutamic acid to proline, by inhibition of transport of proline into fibroblasts, or by interference with the aminoacylation of proline tRNA in the fibroblast.

L-Azetidine-2-carboxylic acid $(\mathrm{AZC})^{1}$ is a naturally occurring proline analogue, which, in bacteria, competes for transport of proline (6) and for aminoacylation of proline tRNA $(7)$. The analogue also produces pro-

This investigation was supported in part with grants from Research Corporation, Burlingame, Calif., and Cámara Nacional de la Industria de Laboratorios Químico-Farmacéuticos, México, D. F.

Received for publication 27 June 1972 and in revised form 15 February 1973.

${ }^{1}$ Abbreviation used in this paper: AZC, L-azetidine-2carboxylic acid. found effects on collagen biosynthesis when added in vitro $(8-10)$ in specific mammalian systems. Collagen synthesized in the presence of AZC is deficient in hydroxyproline, hydroxylysine, and glycosylated hydroxylysine and, in fact, contains several residues of $\mathrm{AZC}$ per molecule. The "collagen" containing the analogue is not extruded from the cells at a normal rate (9). Recently, AZC, at a concentration of $1 \times 10^{-2} \mathrm{M}$, has been shown to inhibit by $50 \%$ the aminoacylation of liver tRNA by proline, ${ }^{2}$ and also to abolish collagen synthesis in chick embryos (11).

The present communication describes experiments in which AZC-injected (i.p.) rats were also being administered $\mathrm{CCl}_{4}$ to produce cirrhosis of the liver. The effects of the analogue were then determined on the pool of proline, the incorporation of proline, and the formation of hydroxyproline in collagen, as well as on the total biosynthesis of collagen.

\section{METHODS}

Three groups of male albino rats weighing 50-100 $\mathrm{g}$ each received $0.15 \mathrm{ml}$ of $\mathrm{CCl}_{4}$ in mineral oil $(1: 7$ by volume) i.p. three times weekly for a total of 20 doses. Group I (control cirrhotics) received no other injection; group II rats were given $10 \mu \mathrm{mol}$ i.p. AZC (Aldrich) with each of the last 10 doses of $\mathrm{CCl}_{4}$; and group III rats received the same amount of AZC with each of the 20 doses of $\mathrm{CCl}_{4}$. Approximately $24-48 \mathrm{~h}$ after the last injection of $\mathrm{CCl}_{4}$ in the control series and of the last injection of both AZC and $\mathrm{CCl}_{4}$ in the experimental group, the animals were exsanguinated by heart puncture and then killed by a blow to the head. The livers were removed immediately and a small portion of the left lateral lobe fixed in $10 \%$ formalin and embedded in paraffin. Thin sections were prepared and stained respectively with hematoxyline, eosin, silver, and sudan stains. Histological examination was kindly performed by Dr. Adolfo Martínez-Palomo, independent of knowledge obtained by chemical studies, the remainder of the liver was sliced and single gram portions used for each of the following determinations.

${ }^{2}$ Díaz de León, L., and M. Rojkind. Unpublished observation. 
Determination of free prolinc. About $1 \mathrm{~g}$ of liver (wet wt) was homogenized with $3 \mathrm{ml}$ of distilled water, and the protein precipitated by addition of $0.5 \mathrm{ml}$ of $20 \%$ perchloric acid. The samples were placed in an ice bath for 10-15 min and the protein then removed by centrifugation at $750 \mathrm{~g}$ for $15 \mathrm{~min}$. The supernatant fluid containing the free amino acids was neutralized with $2 \mathrm{~N} \mathrm{KOH}$ and the precipitated salt removed by centrifugation. Proline was determined as follows: Duplicate aliquots of each sample were oxidized for $20 \mathrm{~min}$ with $1 \mathrm{ml}$ of chloramine- $\mathrm{T}$ solution prepared according to Woessner (12). The reaction was stopped with $0.5 \mathrm{ml}$ of 2 $\mathrm{N}$ sodium thiosulfate followed by addition of $1.0 \mathrm{ml}$ of $1 \mathrm{~N}$ $\mathrm{NaOH}$. The solution was saturated with $\mathrm{NaCl}$, and the product of proline oxidation extracted into $6 \mathrm{ml}$ of toluene by shaking in a Vortex mixer (Scientific Industries, Inc., Queens Village, N.Y.). Up to $1 \mathrm{ml}$ of toluene was incubated at $100^{\circ} \mathrm{C}$ for $60 \mathrm{~min}$ with $3 \mathrm{ml}$ of glacial acetic acid and 3.0 $\mathrm{ml}$ of $3 \%$ ninhydrin in a mixture of acetic and phosphoric acids (13). The oxidation of proline was quantitative from 0.1 to $20 \mu \mathrm{mol}$. The extraction of the oxidation product was almost $100 \%$ after two successive extractions with toluene. The colorimetric reaction with ninhydrin was linear from 0.01 to $0.3 \mu \mathrm{mol}$, and gave the same chromophore previously reported (13) with $\lambda \max$ at $515 \mathrm{~nm}$. The $\mathrm{M}$ extinction coefficient obtained is $2.2 \times 10^{3}$. A detailed description of this method will be published elsewhere. ${ }^{3}$

"In vitro" collagen biosynthesis. Single gram portions of liver slices were placed in a $25 \mathrm{ml}$ Erlenmeyer flask containing $3 \mathrm{ml}$ of Ringer's bicarbonate solution and $1 \mu \mathrm{Ci}$ of ${ }^{14} \mathrm{C}$-labeled proline (sp act, $\left.1 \mu \mathrm{Ci} / \mu \mathrm{mol}\right)$. The samples were incubated for $60 \mathrm{~min}$ a Dubnoff incubator at $37^{\circ} \mathrm{C}$ under an atmosphere of $95 \% \mathrm{O}_{2} ; 5 \% \mathrm{CO}_{2}(2)$. The reaction was stopped by rapidly chilling the flasks; $3 \mathrm{ml}$ of $10 \%$ ice-cold trichloroacetic acid (TCA) was added, and the mixture was then homogenized. The precipitated protein was collected by centrifugation at $750 \mathrm{~g}$ for $15 \mathrm{~min}$, washed twice in succession with $6 \mathrm{ml}$ of $5 \% \mathrm{TCA}$, and collagen extracted with hot $5 \%$ TCA as described previously (2). The extract was dialyzed to remove TCA, and hydrolyzed in 6

\footnotetext{
${ }^{3}$ Rojkind, M., and E. González. 1973. An improved method for determining specific radioactivities of proline- $\mathrm{C}^{14}$ and hydroxyproline- $C^{14}$ in collagen and in noncollagenous proteins. Anal. Biochem. Submitted for publication.
}

$\mathrm{N} \mathrm{HCl}$. The residual protein after TCA extraction (noncollagenous proteins) was also hydrolyzed in $6 \mathrm{~N} \mathrm{HCl}$. Proline was determined as described and hydroxyproline by the method of Woessner (12). The incorporation of radioactive proline into the proline (pro) and hydroxyproline (hypro) of collagen and into the proline of noncollagenous proteins was determined after oxidation with chloramine-T as described below. The oxidation product of proline (see determination of free proline) was extracted into $6 \mathrm{ml}$ of toluene and $4 \mathrm{ml}$ of the toluene layer was transferred into a flask containing $6 \mathrm{ml}$ of toluene and $5 \mathrm{ml}$ of concentrated scintillation fluid of the following composition: $1.2 \% 2,5-$ diphenyloxazole (PPO) and $0.03 \%$ 1,4-bis-[2-(5-phenyloxazolyl)]benzene (POPOP) in toluene. A second aliquot $(1 \mathrm{ml})$ was used for the colorimetric determination of proline. The reaction mixture was extracted twice more with $6 \mathrm{ml}$ of toluene and incubated at $100^{\circ} \mathrm{C}$ for $30 \mathrm{~min}$ in order to convert the oxidation product of hypro into a pyrrole. ${ }^{3}$ After cooling the sample the pyrrole was extracted into 6 $\mathrm{ml}$ of toluene and $4 \mathrm{ml}$ of the toluene layer used for radioactivity determination as described above. Appropriate aliquots of the toluene layer were also used for pyrrole determination with $p$-dimethylaminobenzaldehyde (14). About $20 \%$ of the counts of each proline and hypro were lost since oxidation with chloramine-T promotes decarboxylation of both compounds. The results obtained by this procedure were similar $( \pm 5 \%)$ to the results obtained when the amino acids are purified by ionic exchange chromatography $(3,5)$. The procedure also allows direct determination of the concentration and radioactivity of both amino acids, and hence the specific radioactivities. AZC at a concentration up to 100 times greater than that of proline and hydroxyproline did not interfere with the determination of both imino acids.

All determinations were performed in duplicate, with the livers from three rats in each experimental group.

\section{RESULTS}

The quantity of free proline in the livers of the cirrhotic rats was $0.44 \mu \mathrm{mol} / \mathrm{g}$, a value similar to those reported previously for similar animals (3). As has been demonstrated, the increase in the pool of free proline accompanies an increase in the total collagen content of the

TABLE I

The Pool of Free Proline and the Concentration of Proline and Hydroxyproline in the Collagen of Livers of Treated Rats*

\begin{tabular}{lccc}
\hline & & \multicolumn{2}{c}{ Collagen } \\
\cline { 4 - 4 } & Free proline & Proline & $\begin{array}{c}\text { Hydroxy- } \\
\text { proline }\end{array}$ \\
\hline & $\mu \mathrm{mol} / \mathrm{g}$ & \multicolumn{2}{c}{$\mu \mathrm{mol} / \mathrm{g}$} \\
Group I (cirrhotic) & $0.439 \pm 0.142$ & $4.46 \pm 0.25$ & $3.30 \pm 0.38$ \\
Group II (each rat received 100 $\mu \mathrm{mol} \mathrm{AZC)}$ & $0.362 \pm 0.097$ & $1.93 \pm 0.10$ & $0.88 \pm 0.11$ \\
& $(P<0.20)$ & $(P<0.001)$ & $(P<0.001)$ \\
Group III (each rat received 200 $\mu \mathrm{mol} \mathrm{AZC)}$ & $0.269 \pm 0.119 \ddagger$ & $1.55 \pm 0.15$ & $0.61 \pm 0.13$ \\
& $(P<0.05)$ & $(P<0.001)$ & $(P<0.001)$
\end{tabular}

* Duplicate analysis were performed with the livers of three different animals. Values are means \pm SD. The $P$ values were obtained by the Student's $t$ test, by comparing each of the treated groups (II and III) with the cirrhotics (group I).

$\ddagger$ The $\lambda$ max of the ninhydrin test suggested the presence in addition to proline of $\Delta^{1}$-pyrroline-5carboxylic acid, a normal precursor of proline. 


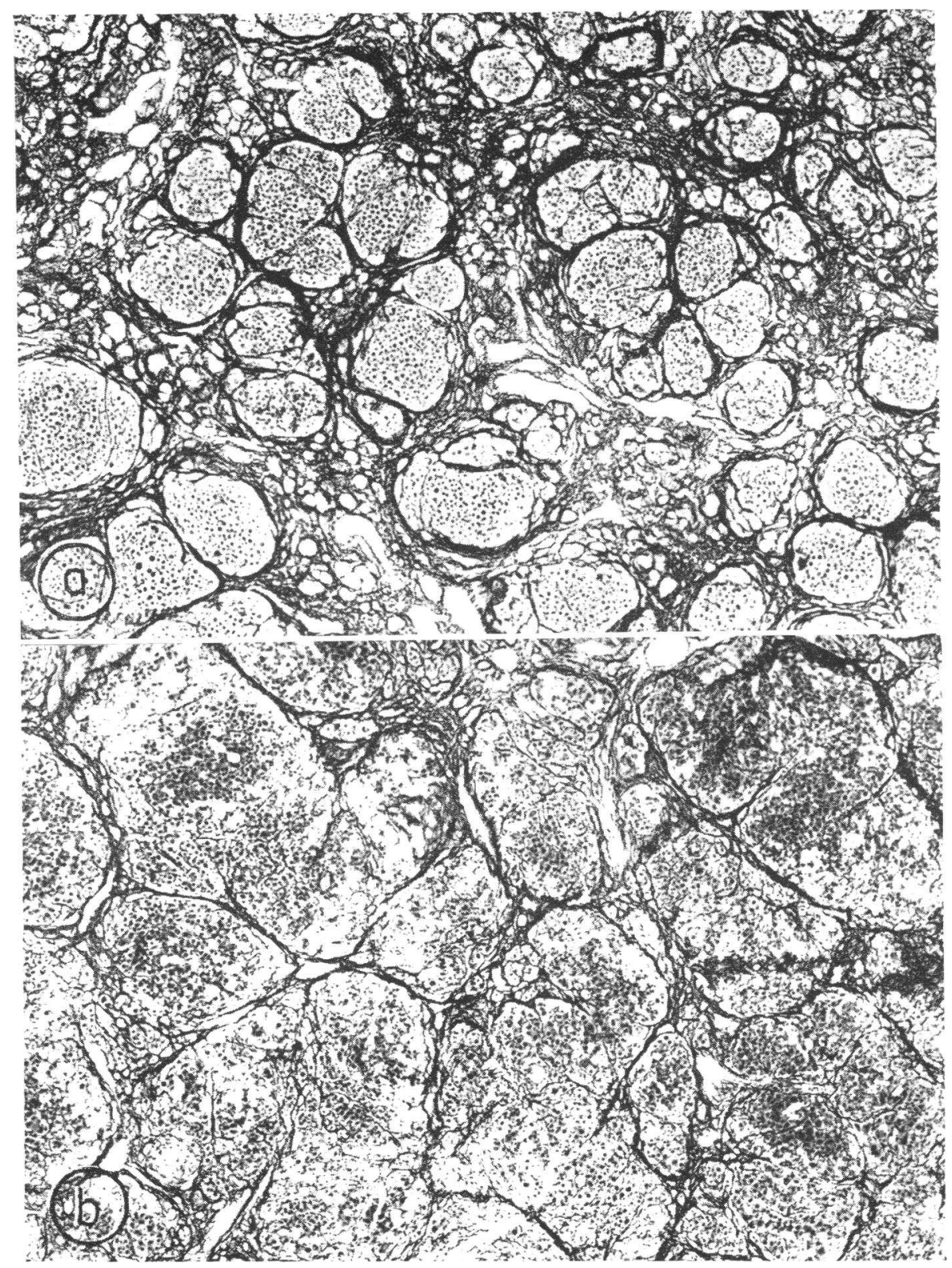

FIGURE 1 (a) Liver section from a $\mathrm{CCl}_{4}$-treated rat. A striking alteration of the normal lobular architecture is seen. Thick bundles of fibrous connective tissue delineate small nodular areas of liver parenchyma. Silver impregnation. $(\times 120)$. (b) Liver section from a rat receiving $\mathrm{CCl}_{4}$ treatment plus AZC. Scarring is considerably less prominent than in livers of animals treated only with $\mathrm{CCl}_{4}$. Parenchymal nodules in the AZC-treated group are larger, and fibrous septa are considerably thinner throughout the liver. Silver impregnation. $(\times 120)$.

livers (see Table I). The extent of hydroxylation of liver collagen was estimated from the mole fraction of hypro/hypro + pro. Thus approximately $44 \%$ of the residues of proline incorporated were hydroxylated. The animals of group II showed a smaller pool of free proline and at the same time a considerable decrease in the amount of collagen. The extent of hydroxylation calculated as described was $31 \%$, a value which is very low and in agreement with the low hydroxylation obtained in other systems (12). The animals of group III contained the lowest proline and collagen values. However, the extent of hydroxylation was similar (29\%) to the value obtained in the group II animals. Histological examination of the liver specimens demonstrated, that the livers of the animals treated with $\mathrm{AZC}$ have the same extent of liver necrosis and cellular regeneration 
TABLE II

Incorporation of Administered $\left[{ }^{14} \mathrm{C}\right]$ Proline into the Proline and Hydroxyproline of Collagen of Liver Slices of Treated Rats*

\begin{tabular}{lcc}
\hline & Proline & $\begin{array}{c}\text { Hydroxy- } \\
\text { proline }\end{array}$ \\
\hline Group I (cirrhotic) & \multicolumn{2}{c}{ total $d p m / g$ of fresh tissue } \\
Group II (each rat received 100 $\mu \mathrm{mol} \mathrm{AZC)}$ & $5,725 \pm 1,604$ & $808 \pm 3$ \\
& $3,146 \pm 326$ & $448 \pm 39$ \\
Group III (each rat received $200 \mu \mathrm{mol} \mathrm{AZC)}$ & $(P<0.05)$ & $(P<0.001)$ \\
& $2,630 \pm 738$ & $448 \pm 82$ \\
& $(P<0.025)$ & $(P<0.001)$ \\
\hline
\end{tabular}

* Duplicate analysis were performed with the livers of three different animals. Values are means \pm SD. The $P$ values were obtained by the Student's $t$ test, by comparing each of the treated groups (II and III) with the cirrhotics (group I).

as do the cirrhotic rate not receiving AZC. However, the extent of fibrosis was greatly diminished. The regeneration nodules were much larger and were surrounded by thin bands of collagen and reticular fibrils (see Fig. 1).

Incorporation of radioactivity into the proline and hydroxyproline of collagen was greatly diminished in the animals treated with AZC. As evident in Table II, the amount of proline incorporated into the hydroxyproline fraction of collagen was $50 \%$ of the value obtained in the cirrhotic animals not receiving the proline analogue.

Since the "in vitro" studies may not always reflect the "in vivo" situation, three rats of the control cirrhotics and three more rats of group II (AZC treated) were injected in vivo with uniformly labeled $\left[{ }^{14} \mathrm{C}\right]$ proline. $48 \mathrm{~h}$ after the last dose of $\mathrm{CCl}_{4}$, each animal received three doses (i.p.) of $5 \mu \mathrm{Ci}$ each of proline (specific radioactivity $220 \mathrm{mCi} / \mathrm{mmol}$ ) every $8 \mathrm{~h}$, and $4 \mathrm{~h}$ after the last isotope injection, they were sacrificed. $1-\mathrm{g}$ portions of the livers were used for determining the specific activity of collagen-hydroxyproline. The specific activity of hydroxyproline in the control cirrhotics was $456 \pm 53$ $\mathrm{dpm} / \mu \mathrm{mol}$ and that of the AZC-treated animals was $229 \pm 32 \mathrm{dpm} / \mu \mathrm{mol}$. These results indicate that the percent inhibition of collagen biosynthesis in vitro and in vivo are of the same order of magnitude.

In view of the dramatic effect of $\mathrm{AZC}$ on the incorporation of proline into the collagen of livers of $\mathrm{CCl}_{4}$ treated rats, the incorporation of radioactivity into the noncollagenous protein in the liver was determined. The data in Table III show that the incorporation of proline into the noncollagenous proteins was very similar in the livers of cirrhotic animals and in the $\mathrm{CCl}_{4}$-treated animals treated with AZC. Neither hydroxyproline or radioactivity derived from hydroxyproline was detected in this fraction.

\section{DISCUSSION}

Little information exists regarding the regulation of the early steps of collagen biosynthesis. Finerman and Rosenberg (15), Finerman, Downing, and Rosenberg

TABLE III

Incorporation of $\left[{ }^{14} \mathrm{C}\right]$ Proline into the Proline of Total Noncollagenous Proteins of Liver Slices of Treated Rats*

\begin{tabular}{lcc}
\hline & Proline & $\begin{array}{c}\text { Specific } \\
\text { activity } \ddagger\end{array}$ \\
\hline Group I (cirrhotic) & $\mu \mathrm{mol} / \mathrm{g}$ & \\
Group II (each rat received $100 \mu \mathrm{mol} \mathrm{AZC)}$ & $61.0 \pm 3.7$ & $1,809 \pm 617$ \\
Group III (each rat received $200 \mu \mathrm{mol} \mathrm{AZC)}$ & $54.4 \pm 6.5$ & $1,864 \pm 218$ \\
& $(P<0.10)$ & $(P<0.20)$ \\
& $(P<0.1 \pm 7.5$ & $1502 \pm 349$ \\
& $(P<0.20)$ & $(P<0)$ \\
\hline
\end{tabular}

* Duplicate analysis were performed with the livers of three different animals. Values are means \pm SD. The $P$ values were obtained by the Student's $t$ test, by comparing each of the treated groups (II and III) with the cirrhotics (group I).

$\ddagger$ Expressed as disintegrations/minute per micromole. 
(16) and Phang, Finerman, Singh, Rosenberg, and Berman (17). working with fetal rat calvaria, and Rojkind and Díaz de León (3) and Kershenobich, Fierro, and Rojkind (5) using cirrhotic rat and human livers obtained information suggesting that the pool of free proline is important in the regulation of collagen biosynthesis. Accordingly, compounds interfering with transport or biosynthesis of proline should inhibit collagen biosynthesis. The present studies demonstrate that rats treated with $\mathrm{AZC}$ developed a lesser degree of cirrhosis and their livers contained a smaller pool of free proline when compared with the untreated cirrhotic rats. The decrease in the pool of free proline suggests that AZC either inhibits proline biosynthesis or interferes with the active transport of this amino acid into hepatic fibroblasts. However, no substantial evidence exists in support of either suggestion.

Preliminary studies performed by Díaz de León and Rojkind ${ }^{4}$ have shown that $\mathrm{AZC}$ at a concentration of $1 \times 10^{-2} \mathrm{M}$ inhibits acylation of tRNA by proline $50 \%$ in the test tube, and that changes in the pool sizes of amino acids in the cirrhotic liver are accompanied by large changes in the in vivo ability of tRNA to become acylated with specific amino acids. The above results, as well as the results of Lanks and Weinstein (18) and Mäenpää and Ahonen (19), further stress the importance of both the pool size of free proline and the acylated tRNA in the regulation of collagen biosynthesis. Accordingly, changes of the pool of proline in vitro should not be expected by themselves to significantly alter the rate of proline incorporation into collagen.

When administered to rats concurrently with cirrhogenic doses of $\mathrm{CCl}_{1}, \mathrm{AZC}$ caused a decreased incorporation of labeled proline into collagen. Since AZC is to some extent incorporated into collagen (9), one might speculate that such peptide bonds may be labile and could be cleaved during the extraction with hot TCA. Should this occur, a portion of the protein could be lost in the subsequent dialysis. Furthermore, since the incorporated AZC does not become hydroxylated and appears to interfere with the normal hydroxylation of proline $(8,9)$, the measured amount of hydroxyproline or the specific radioactivity may not truly reflect the extent of collagen synthesis. As can be seen in Table I and II, the amount of hydroxyproline in the AZC-treated animals is low, the incorporation of $\left[{ }^{14} \mathrm{C}\right]$ proline is also low; however, the specific radioactivity is high. Nevertheless, histological sections stained for collagen and reticular fibrils showed a reduced amount of collagen in livers of cirrhotic rats treated with AZC as compared with those not so treated. The histological findings together with the decreased incorporation of

\footnotetext{
' Díaz de I eón, L., and M. Rojkind. Unpublished observation.
}

proline into collagen-hydroxyproline both in vitro and in vivo, suggest that indeed $A Z C$ inhibits collagen synthesis and deposition in the cirrhotic liver.

The modifications of collagen that occur after synthesis, such as hydroxylation of proline and lysine residues. glycosylation of hydroxylysine residues (20), and transcellular movement of collagen are also subject to regulation. Ehrlich and Bornstein (21) and Diegelmann and Peterkofsky (22) have shown that colchicine, which alters nicrotubule formation, also inhibits the transcellular transport of collagen. In this context Rojkind. Uribe, and Kershenobich (23) have recently shown that colchicine administered to $\mathrm{CCl}_{1}$-treated rats inhibits the incorporation of proline into collagen and also improves some of the abnormal liver function tests of the cirrhotic animals and patients (23). The above results suggest that a better knowledge of the steps involved in regulation of collagen biosynthesis may allow the development of a more rational therapy for liver fibrosis.

\section{ACKNOWLEDGMENTS}

I am indebted to Professor Ruy Pérez-Tamayo for his help in preparing this manuscript and for many stimulating discussions, and to Dr. Adolfo Martínez-Palomo for his kind help in the histological studies.

\section{REFERENCES}

1. Popper, H., and S. Udenfriend. 1970. Hepatic fibrosis correlation of biochemical and morphologic investigation. Am. J. Med. $49: 707$.

2. Huberman, A., A. Recio, and M. Rojkind. 1969. Collagen biosynthesis in normal and cirrhotic rat liver slices. Proc. Soc. Exp. Biol. Med. 131: 200.

3. Rojkind, M., and L. Díaz de León. 1970. Collagen biosynthesis in cirrhotic rat liver slices: a regulatory mechanism. Biochim. Biophy's. Acta. 217: 512.

4. Feinman, L., and C. S. Lieber. 1972. Hepatic collagen metabolism. Effect of alcohol consumption in rats and baboons. Science (Wash. D. C.). 176: 795.

5. Kershenobich, D., F. J. Fierro, and M. Rojkind. 1970. The relationship between the free pool of proline and collagen content in human liver cirrhosis. J. Clin. Invest. 49: 2246.

6. Fowden, L., and M. H. Richmond. 1963. Replacement of proline by azetidine-2-carboxylic acid during biosynthesis of protein. Biochim. Biophy's. Acta. 71: 459 .

7. Papas, T. S., and A. H. Mehler. 1970. Analysis of the amino acid binding to the proline transfer ribonucleic acid synthetase of Escherichia coli. J. Biol. Chem. 245: 1588.

8. Takeuchi, T., and D. J. Prockop. 1969. Biosynthesis of abnormal collagens with amino acid analogues. I. Incorporation of L-azetidine-2-carboxylic acid and cis-4fluoro-L-proline into protocollagen and collagen. Biochim. Biophy's. Acta. $175: 142$.

9. Takeuchi, T., J. Rosenbloom, and D. J. Prockop. 1969. Biosynthesis of abnormal collagens with amino acid analogues. II. Inability of cartilage cells to extrude collagen polypeptides containing L-azetidine-2-carboxylic acid or cis-4-fluoro-L-proline. Biochim. Bioply's. Acta. $175: 156$. 
10. Rosenbloom, J, and D. J. Prockop. 1970. Incorporation of 3,4-dehydroproline into protocollagen and collagen. Limited hydroxylation of proline and lysine in the same polypeptide. J. Biol. Chem. $245: 3361$.

11. Lane, J. M., P. Dehm, and D. J. Prockop. 1971. Effect of the proline analogue azetidine-2-carboxylic acid on collagen synthesis in vivo. I. Arrest of collagen accumulation in growing chick embryos. Biochem. Biophys. Acta. 236: 517.

12. Woessner, J. F., Jr. 1961. The determination of hydroxyproline in tissue and protein samples containing small proportions of this imino acid. Arch. Biochem. Biophys. 93: 440 .

13. Troll, W., and J. Lindsley. 1955. A photometric method for the determination of proline. J. Biol. Chem. 215: 655.

14. Peterkofsky, B., and D. J. Prockop. 1962. A method for the simultaneous measurement of the radioactivity of proline- $\mathrm{C}^{14}$ and hydroxyproline- $\mathrm{C}^{14}$ in biological materials. Anal. Biochem. 4: 400.

15. Finerman, G. A. M., and L. E. Rosenberg. 1966. Amino acid transport in bone. Evidence for separate transport systems for neutral amino and imino acids. J. Biol. Chem. 241: 1487.

16. Finerman, G. A. M., S. Downing, and L. E. Rosenberg. 1967. Amino acid transport in bone. II. Regulation of collagen synthesis by perturbation of proline transport. Biochim. Biophys. Acta. 135 : 1008.

17. Phang, J. M., G. A. M. Finerman, B. Singh, L. E Rosenberg, and M. Berman. 1971. Compartmental analysis of collagen synthesis in fetal rat calvaria. I. Perturbation of proline transport. Biochim. Biophys. Acta. $230: 146$

18. Lanks, K. W., and B. Weinstein. 1970. Quantitative differences in proline tRNA content of rat liver and granulation tissue. Biochem. Biophys. Res. Commun. $40: 708$.

19. Mäenpää, P. H., and J. Ahonen. 1972. Transfer RNA changes in rat granulation tissue possibly related to collagen synthesis. Biochem. Biophys. Res. Commun. 49: 179 .

20. Grant, M. E., and D. J. Prockop. 1972. The biosynthesis of collagen. N. Engl. J. Med. 286: 242.

21. Ehrlich, H. P., and P. Bornstein. 1972. Microtubules in transcellular movement of procollagen. Nat. New Biol. 238: 257.

22. Diegelmann, R. F., and B. Peterkofsky. 1972. Inhibition of collagen secretion from bone and cultured fibroblasts by microtubular disruptive drugs. Proc. Natl. Acad. Sci. U. S. A. 69: 892.

23. Rojkind, M., M. Uribe, and D. Kershenobich. 1973. Colchicine and treatment of liver cirrhosis. Lancct. 7793: 38. 